\title{
Treatment of middle cerebral artery (MCA) aneurysms: a review of the literature
}

\author{
Wuyang Yang and Judy Huang*
}

\begin{abstract}
Microsurgical treatment is well established as the preferred strategy for definitive obliteration of middle cerebral artery (MCA) aneurysms. However, increasing reports on the feasibility and efficacy of endovascular treatment of MCA aneurysms in large case series suggest coiling as a viable alternative to microsurgery. This review provides a critical overview of the current literature regarding MCA aneurysm treatment, with the objective to clarify the available evidence of efficacy with microsurgical compared to endovascular treatment.
\end{abstract}

Keywords: Middle cerebral artery; Aneurysm; Endovascular; Surgery

\section{Introduction}

Management strategies for intracranial aneurysms have changed dramatically over the past decades. Endovascular treatment has been increasingly adopted as the primary procedure for a wide spectrum of aneurysms [1-6]. The decision to pursue endovascular treatment over microsurgical treatment is particularly appealing for patients as the procedures are safe, are less invasive, and do not affect the patient from a cosmetic point of view [2]. Comparative treatment efficacy of an endovascular approach was evaluated in the multicenter randomized control trial (RCT) conducted by the International Subarachnoid Aneurysm Trial (ISAT) group in 2002, in which the early results at 1-year follow-up suggested superiority of coiling compared to clipping [7]. In response to ISAT, which resulted in the widespread adoption of a "coil first" policy, the Barrow Ruptured Aneurysm Trial (BRAT) was conducted in 2003 with the emphasis on treatment selection strategy in the presence of clinical equipoise. The results released in 2012 confirmed the conclusions in the ISAT trial with coiling demonstrating a significant absolute risk reduction of $10.5 \%$ when compared to clipping at 1-year follow-up [8].

Despite the endorsement of endovascular treatment by early outcome results in both studies as an excellent option for ruptured intracranial aneurysm treatment, the uncertainty between "coil first" and "clip first" approaches

\footnotetext{
* Correspondence: jhuang24@jhmi.edu

Department of Neurosurgery, Johns Hopkins University School of Medicine, Zayed Tower, Suite 6115F, 1800 Orleans Street, Baltimore, MD 21287, USA
}

continued as long-term follow-up was awaited to confirm the advantage of coiling over clipping. Ultimately, longterm follow-up outcomes in both studies were evaluated at 18 and 3 years, respectively, and an attenuation of the benefit gain achieved by endovascular treatment became evident, to the point where no significant difference of neurological outcomes at long-term follow-up was observed between the two treatment groups [9-12]. In addition, the authors have also identified an increase in suboptimal secondary outcomes in the endovascular arm, including higher re-bleeding risk, lower obliteration rate, and higher retreatment rate, which are known limitations of endovascular treatment [1, 9, 12-15]. The emergence of adverse events following endovascular treatment warrants an even longer follow-up for these studies to fully appreciate the treatment efficacy of endovascular treatment.

\section{Review}

\section{General characteristics}

The middle cerebral artery (MCA) is a direct extension of the internal cerebral artery (ICA) and is divided into four segments (M1-M4). The prevalence of MCA aneurysms is approximately $14.0-43.0 \%$ among all cerebral aneurysms [6-10, 16-18]. These aneurysms are usually observed to arise from the M2 bifurcation segment or the proximal M1 segment [16, 19-24]. Rinne et al. explored anatomical and clinical features of MCA aneurysms in a Finnish population of 1314 consecutive patients. According to their observations, $42.6 \%$ of all aneurysm patients have at least one MCA aneurysm, in which $20.0 \%$ 
Table 1 Summary of studies on MCA aneurysms

\begin{tabular}{|c|c|c|c|c|c|c|c|c|c|}
\hline Study name & $\begin{array}{l}\text { Study } \\
\text { period }\end{array}$ & $\begin{array}{l}\text { Number of } \\
\text { patients }\end{array}$ & $\begin{array}{l}\text { Mean/median } \\
\text { age }\end{array}$ & $\mathrm{SAH}$ & $\begin{array}{l}\text { MCA aneurysm } \\
\text { size }\end{array}$ & $\begin{array}{l}\text { Follow-up } \\
\text { (months) }\end{array}$ & Good outcome & $\begin{array}{l}\text { Occlusion } \\
\text { rate (\%) }\end{array}$ & $\begin{array}{l}\text { Recurrer } \\
\text { rate (\%) }\end{array}$ \\
\hline \multicolumn{10}{|l|}{ Surgical series } \\
\hline Suzuki et al. [23] & $1961-1981$ & 413 & - & $259(97.7 \%)^{a}$ & - & $0^{b}$ & $85.0 \%$ & - & - \\
\hline \multirow[t]{4}{*}{ Rinne et al. [16] } & 1977-1992 & 561 & 48.9 & $513(91.4 \%)^{c}$ & 2-7 mm: 141 & 12 & $62 \%($ GOS $\leq 2)$ & - & - \\
\hline & & & & & 8-14 mm: 104 & & & & \\
\hline & & & & & 15-24 mm: 38 & & & & \\
\hline & & & & & $\geq 25 \mathrm{~mm}: 17$ & & & & \\
\hline Ogilvy et al. [32] & 1985-1989 & 62 & - & - & - & 1 & $82.3 \%$ & - & - \\
\hline \multirow[t]{4}{*}{ Morgan et al. [34] } & 1989-2009 & 263 & 52.7 & $0(0.0 \%)$ & $<7$ mm: 153 & 1.5 & $94.7 \%(m R S \leq 1)$ & - & - \\
\hline & & & & & 7-14 mm: 81 & & & & \\
\hline & & & & & 15-24 mm: 26 & & & & \\
\hline & & & & & $\geq 25 \mathrm{~mm}: 20$ & & & & \\
\hline \multirow[t]{2}{*}{ Rodriguez-Hernandez et al. [15] } & 1997-2010 & 543 & 55.3 & $282(51.9 \%)$ & "Giant": 30 & $46.8^{d}$ & SAH: $92.0 \%$ & 98.3 & 3.8 \\
\hline & & & & & & & UR: $72.0 \%(m R S \leq 2)$ & & \\
\hline \multirow[t]{3}{*}{ Van Dijk et al. [1] } & $2001-2006$ & 105 & 52.3 & $77(73.3 \%)$ & $<6$ mm: 37 & 56.4 & $80 \%(m R S \leq 2)$ & 89 & - \\
\hline & & & & & 6-10 mm: 54 & & & & \\
\hline & & & & & $>10$ mm: 25 & & & & \\
\hline \multirow[t]{2}{*}{ Choi et al. [47] } & 2007-2010 & 125 & 58 & $0(0.0 \%)$ & $<5$ mm: 89 & 22.5 & $100.0 \%$ & 95.8 & 0 \\
\hline & & & & & 5-10 mm: 54 & & & & \\
\hline \multicolumn{10}{|l|}{ Endovascular series } \\
\hline \multirow[t]{3}{*}{ Suzuki et al. [41] } & 1990-2007 & 115 & 55.1 & 48 (41.7 \%) & $<10$ mm: 81 & 15.5 & $82.6 \%(\mathrm{mRS} \leq 2)$ & 46.0 & 10.0 \\
\hline & & & & & 11-25 mm: 22 & & & & \\
\hline & & & & & $>25$ mm: 12 & & & & \\
\hline \multirow[t]{4}{*}{ Bracard et al. [37] } & 1992-2001 & 140 & - & $73(48.0 \%)^{\mathrm{e}}$ & $<4$ mm: 37 & 51.6 & $89.3 \%(\mathrm{GOS} \leq 2)$ & 84.2 & 9.1 \\
\hline & & & & & 4-10 mm: 90 & & & & \\
\hline & & & & & 11-20 mm: 12 & & & & \\
\hline & & & & & $>20$ mm: 13 & & & & \\
\hline \multirow[t]{3}{*}{ Mortimer et al. [49] } & 1996-2012 & 295 & 53.7 & $242(82.0 \%)$ & <10 mm: 232 & 35 & $87.1 \%$ (GOS $\leq 3)$ & 69.4 & 30.5 \\
\hline & & & & & 11-24 mm: 64 & & & & \\
\hline & & & & & $\geq 25 \mathrm{~mm}: 4$ & & & & \\
\hline Kadkhodayan et al. [38] & 1996-2013 & 292 & 56.5 & $95(27.5 \%)^{f}$ & $6.6 \mathrm{~mm}$ & 24 & $97.1 \%^{9}$ & 68.5 & 8.2 \\
\hline lijima et al. [40] & 1998-2002 & 137 & 48 & $72(46.8 \%)^{\mathrm{h}}$ & $7 \mathrm{~mm}$ & 15 & $89.8 \%$ (mRS $\leq 3)$ & 77.2 & 20.0 \\
\hline Vendrell et al. [48] & 1999-2006 & 153 & 49.5 & 98 (64.1\%) & <7 mm: 104 & 50 & $92.9 \%(\mathrm{GOS} \leq 2)$ & 64.0 & 27.2 \\
\hline
\end{tabular}


Table 1 Summary of studies on MCA aneurysms (Continued)

\begin{tabular}{|c|c|c|c|c|c|c|c|c|c|}
\hline \multirow[t]{2}{*}{ Güresir et al. [35] } & 1999-2009 & E: 59 & E: - & E: 38 (64.4 \%) & $\mathrm{E}: 7 \mathrm{~mm}$ & 60 & E: $69.5 \%$ & E: 65 & E: 6.8 \\
\hline & & S: 271 & S: 50.4 & S: 163 (60.1\%) & $\mathrm{s}: 7 \mathrm{~mm}$ & & S: $71.2 \%$ & S: 98 & s: 0 \\
\hline \multirow[t]{2}{*}{ Taha et al. [39] } & 2001-2004 & 133 & 60.28 & $53(39.8 \%)$ & $7.21 \mathrm{~mm}$ & 26.7 & SAH: E: $62 \%$, S: $44 \%$ & E: 57.5 & - \\
\hline & & & & & & & UR: E: 93 \%, S: 81 \% & S: 81.4 & \\
\hline \multirow[t]{2}{*}{ Diaz et al. [30] } & 2005-2010 & E: 50 & E: 57.7 & E: 10 (20.0 \%) & $\mathrm{E}: 7.12 \mathrm{~mm}$ & 9.02 & E: $90.0 \%$ & E: 86 & E: 14 \\
\hline & & S: 34 & S: 57.7 & S: 9 (26.5 \%) & $\mathrm{S}: 6.0 \mathrm{~mm}$ & & S: $94.1 \%$ & S: 95 & $\mathrm{~s}: 0$ \\
\hline \multirow[t]{2}{*}{ Kim et al. [4] } & 2008-2011 & E: 30 & E: 56.7 & E: 3 (10.0 \%) & - & $0.25-6$ & E: $86.7 \%$ & E: 93 & - \\
\hline & & S: 78 & S: 58.5 & S: 9 (11.5\%) & & & S: $93.5 \%$ & S: 92 & \\
\hline
\end{tabular}

7-12 mm: 59

13-24 mm: 11

$\geq 25 \mathrm{~mm}: 0$

Doerfler et al. [50]

$2001-2005$

31

48.3

$15(48.4 \%)$

$<6 \mathrm{~mm}: 24$

6-10 mm: 7

$>10 \mathrm{~mm}: 7$

Brinjiki et al. [36]

Regli et al. [42]

2002-2009

36

60

$6(16.7 \%)$

$-$

$<6 \mathrm{~mm}: 18$

6-10 mm: 11

11-25 mm: 4

$25 \mathrm{~mm}: 1$

6

$82.4 \%$

86.8

20.0

SAH subarachnoid hemorrhage, $E$ endovascular, $S$ surgery, UR unruptured

${ }^{a}$ The authors only reported number of ruptured cases in 265 patients with single aneurysm

Outcomes were evaluated at time of discharge

'Long term follow-up for 106 patients out of 480 eligible patients (22\%)

${ }^{\mathrm{d} A}$ total of 513 patients presented with SAH, 438 were attributable to MCA aneurysms

'The authors reported 140 patients with $152 \mathrm{MCA}$ aneurysm, among which 73 aneurysms ruptured $(48.0 \%)$

${ }^{f}$ The authors reported 292 patients with 346 MCA aneurysms, among which 95 aneurysms ruptured (27.5\%)

${ }^{9}$ Clinical outcome was only observed at 30 -day post-op

${ }^{\mathrm{h}}$ The authors reported 137 patients with 149 MCA aneurysms, among which 72 aneurysms ruptured (48.3\%) 
have multiple MCA aneurysms, $17.8 \%$ have bilateral MCA aneurysms, and $11.2 \%$ have mirror MCA aneurysms [16]. Most of the MCA aneurysms (45\%) are laterally projecting, with $38 \%$ inferiorly pointing, $15 \%$ superiorly projecting, and only $2 \%$ medially pointing.

A positive family history of aneurysms is found in $11 \%$ of all patients bearing a single aneurysm and may increase to $22 \%$ when the patient has bilateral MCA aneurysms [16]. Risk of rupture is affected by multiple factors such as large size, irregular dome morphology, cigarette smoking, use of illicit drugs, hypertension and female sex $[17,25-29]$. The annual risk of rupture is reported to be $0.0 \%-8.0 \%$ depending on the size of the aneurysm $[16,17,24,28]$.

\section{Trend for MCA aneurysm management}

In contrast to the treatment of most posterior circulation aneurysms where there is an evident advantage of endovascular compared to surgical approaches regarding ease of access and treatment outcomes, the selection of treatment for MCA aneurysms consistently favors microsurgical management $[1,2,15,24,30,31]$. The relatively superficial location of MCA aneurysms permits easy surgical access with minimal frontal or temporal lobe retraction, thereby resulting in excellent prognosis $[1,15,16,20-23,32-35]$. In addition, typical MCA aneurysm morphology is considered unsuitable for an endovascular approach as the majority of these aneurysms are distant to access and are usually broad-necked with undesirable dome-to-neck ratios $[15,16]$. However, with recent advancement of endovascular techniques and devices, and with endovascular aneurysm management established by the ISAT and other studies, there is an emerging interest in the exploration of MCA aneurysm management by endovascular approaches [4, 36-41]. In a recent systematic review of MCA aneurysm treatment by Blackburn et al. in 2014, the authors performed a comprehensive search of all MCA aneurysm-related articles between 2004 and 2013, and 23 published series were included in this study, with 839 aneurysms treated by coiling and 1052 aneurysms treated surgically [31]. Another systematic review focusing on endovascular treatment included 11 studies with a total of 1076 MCA aneurysms treated via endovascular approach between 1990 and 2009 [36]. We provided a summary of major studies on MCA aneurysm in Table 1. The substantial growth in the number of MCA aneurysm patients treated by coiling demonstrates an increasing interest in exploring the feasibility of coiling as an alternative option in MCA aneurysm management.

Although there is a dramatic increase of interest in endovascular management of MCA aneurysms, the evidence to advance coiling as a strategy for MCA aneurysm management is inadequate. When examining the shortterm (1 year) follow-up results in ISAT, patients bearing
MCA aneurysms are the only subgroup in which superiority of clipping compared to coiling regarding treatment outcomes was demonstrated [10]. In addition, as suggested by Rodriguez and authors [15], the distribution of aneurysm locations in the ISAT study is significantly different from what was previously reported, with MCA aneurysms comprising only $14.0 \%$ of all aneurysms in ISAT as compared to approximately $25.0 \%$ in reported literature, suggesting a potential sampling bias that favors maximizing outcome in the coiling group. Furthermore, current available comparative studies and meta-analyses on MCA aneurysm treatment suggested slight to moderate advantage of clipping over coiling [24, 30, 31, 42]. Therefore, further investigation is warranted for justification of endovascular therapy as a viable alternative to surgical therapy in definitive treatment of MCA aneurysms.

\section{The surgical perspective of MCA aneurysm treatment}

Techniques regarding surgical management of MCA aneurysms have been well established since the age of Dandy [43]. As proposed by Washington and authors, the majority of MCA bifurcation aneurysms can be easily categorized into four distinct categories with recommended clipping strategy illustrated in detail for each of the category [44].

Most MCA aneurysms can be directly viewed after a pterional or minipterional craniotomy combined with arachnoid dissection through the Sylvian fissure corridor with minimal brain retraction $[16,45]$. The surgical field can be widely opened with minimal manipulation of surrounding brain tissue to provide sufficient exposure of the aneurysm and the related MCA vessels, with ability to maneuver for clip application. Direct view of MCA branches is also critical in recognizing potential perforators that may not be appreciated on digital subtraction angiography (DSA) due to limitations of two-dimensional imaging modality. The implementation of adjunctive intraoperative tools including continuous somatosensory evoked potential (SSEP) and electroencephalography (EEG) monitoring, indocyanine green (ICG) angiography, and intraoperative DSA improve surgical outcomes by providing critical information regarding optimal clip placement $[33,46]$.

Excellent outcomes can be achieved via a microsurgical approach when cases are carefully selected and planned. According to previous reports, good outcomes were reported in 70-100 \% MCA aneurysm patients who underwent clipping, with $70-80 \%$ for ruptured patients and $92-100 \%$ for the unruptured cohort $[1,15,16,24,30,34,47]$. Aneurysm occlusion rates were reported to be 90-98.3\% $[1,15]$. Overall mortality rate in post-operative and follow-up periods were reported to be around $5 \%$ but varies greatly depending on the underlying severity of disease at presentation [15, 20-23]. Major complications 
associated with MCA aneurysm clipping were vasospasm, re-bleeding, epilepsy, hemiparesis, and visual field deficits $[1,15,16,34]$. Patients presenting with subarachnoid hemorrhage (SAH), a higher Hunt and Hess grade, and larger size aneurysms have significantly worse outcomes $[1,15,16]$.

Under specific circumstances, surgery harbors significant advantages when considering treatment options for MCA aneurysms. For patients presenting with a distal MCA aneurysm where catheter manipulation is challenging due to distal location on small caliber vessels, clipping is preferred over coiling to minimize procedural risk and ensure optimal outcome [48]. In addition, for patients presenting with ruptured MCA aneurysms accompanied by a large intraparenchymal hematoma, open surgery combining aneurysm clipping, hematoma evacuation, and possibly hemicraniectomy is critical for relief of intracranial pressure to optimize patient outcome.

\section{The endovascular perspective of MCA aneurysm treatment}

In contrast to anatomical considerations favoring microsurgical treatment for successful management of MCA aneurysms, endovascular neurosurgeons must overcome technical challenges regarding the unique anatomical features of MCA aneurysms. MCA aneurysms are mostly located on the proximal M1 or MCA bifurcation, which is relatively distal compared to common locations preferable for endovascular treatment. The narrowing of the arterial lumen beginning from the proximal MCA also poses procedural challenges to advancing flexible catheters with larger outer diameter into distant MCA arteries against increasing vessel resistance. The majority of MCA aneurysms are also reported to present with a wide-necked base, which are considered suboptimal for endovascular management. In addition, the visualization of MCA aneurysms may be relatively limited due to overlapping trunks of the MCA bifurcation or trifurcation on DSA.

Despite technical disadvantages, emerging interest has arisen during the past decade on the feasibility of coiling as an option in MCA aneurysm management. Continued innovations in endovascular techniques and devices were introduced to overcome these technical challenges, including stent assisted coiling, catheter enhancement with increased inner diameter and flexibility, balloon remodeling, and three-dimensional rotational angiography. In an early report by Iijima et al. in 2005 with a case series of 149 MCA aneurysm patients, overall mortality and morbidity rate was 6 and $1 \%$ for ruptured aneurysms and 1 and $3 \%$ for unruptured aneurysms, respectively [40]. The reported outcomes are comparable and even appeared to be superior when compared with microsurgical treatment. However, only $77.2 \%$ of all patients achieved complete occlusion of the aneurysm. The authors also identified a $20.0 \%$ recurrence rate at 15 months follow-up, in which $11.4 \%$ required retreatment. Following this study, multiple studies regarding feasibility and efficacy of endovascular treatment in MCA aneurysm management have been reported [4, 36-38, 40, 49-51]. A recent series reported by Kadkhodayan et al. in 2014 including 292 patients and $346 \mathrm{MCA}$ aneurysms demonstrated an intraoperative thromboembolic event rate of $13.6 \%$, overall morbidity rate of $2.9 \%$ at 30-day follow-up and complete or near complete occlusion rate of $91.8 \%$, with an average of 2 years of follow-up [38]. These endovascular studies on MCA aneurysm management achieved outcomes comparable to surgical management and established the consideration of extending the "coil first" policy to MCA aneurysm management.

\section{Clip versus coil for MCA aneurysm treatment}

To our knowledge, no RCT has compared safety and efficacy of MCA aneurysm treatment between the two modalities. Most direct comparisons were reported in the form of retrospective or prospective observational studies. Regli and authors described the first series of comparison between the two modalities for MCA aneurysm management in a single cohort; they observed a failure rate of $85.0 \%$ in coiling, with only two patients successfully treated by coiling with a "coil first" policy [42]. Despite the excellent surgical result achieved with only $3 \%$ morbidity, the primary limitation is that the study cohort was selected from 1993 to 1997, suggesting that the study is representative of outdated endovascular techniques and devices. A most recent comparison conducted by Diaz et al. in 2014 included patients from 2005 to 2010, with the selection criteria bearing a moderate disadvantage towards surgery, where only large MCA aneurysms with unfavorable dome-to-neck ratio were recommended to undergo clipping for unruptured patients and a "coil first" strategy was implemented for all ruptured MCA aneurysm patients in the absence of a contraindication. The authors observed comparable results in poor outcomes for coiling (10.0\%) and clipping $(5.9 \%)$ with a slight advantage towards clipping. They also reported a $14.0 \%$ retreatment rate for coiling group in comparison to none in the clipping group in a 9-month follow-up period [30]. Although no significant difference was observed for functional outcomes at follow-up, coiling was still associated with more procedural complications (16.0 versus $0.0 \%$ ) and higher retreatment rates. The difference in poor outcome approached near statistical significance for the unruptured group $(p=0.066)$, in which five patients $(12.5 \%)$ had poor outcomes in the endovascular cohort compared to none in the surgical group. Their results were supported by evidence from systematic reviews and meta-analysis of the current literature that 
demonstrated slight to moderate advantage of clipping over coiling in treatment of MCA aneurysms [24, 31].

Despite both management strategies demonstrating acceptable treatment outcomes, reviews including studies reporting case series with a single treatment modality may suffer from multiple potential biases, thereby limiting the interpretation of results generated by systematic reviews and meta-analyses. As suggested by Rodriguez-Hernandez et al., the treatment outcome was very likely biased by the institutional or operator policy on treatment selection, in which operator preference favors one treatment over another [15]. In their series of 631 MCA aneurysms managed with a "clip first" policy, good or unchanged patient functional outcome is achieved in $93 \%$ of unruptured aneurysms and in $87 \%$ of subarachnoid hemorrhage patients, with an overall occlusion rate of $98.3 \%$. Other large series that demonstrated surgical expertise in managing aneurysms have achieved similar results [16, 23, 34]. However, despite the advantage of optimal outcome, lower long-term complications, and lower retreatment rates in clipping, with increasing adoption of "coil first" policy in various centers, the decreased caseload compromising microsurgical skills has become concerning as a potential cause of decline of favorable surgical outcomes in current and future studies $[1,15]$.

Another bias associated with these studies is related to the incomplete observation of outcomes due to short follow-up period. Although endovascular series continue to demonstrate acceptable functional outcomes in the short-term, the "unchanged or improved" functional outcome is most likely attributable to a less invasive approach rather than actual reduced risk of subsequent bleeding. The persistent risk of hemorrhage leading to significant mortality and morbidity as a consequence of residual or recurrent aneurysm is not taken into account when calculating functional outcomes at short-term follow-up. Furthermore, functional outcome measurement does not consider the procedural risks, quality of life impact, and cost in patients receiving multiple treatments. Therefore, in the absence of unbiased studies demonstrating non-inferiority of outcomes in coiling versus clipping, and with the best available evidence suggesting superiority in functional outcome, high occlusion rate, and low retreatment rate for management of MCA aneurysms in surgical series, microsurgical clipping remains the treatment of choice for definitive MCA aneurysm treatment.

\section{Conclusions}

An endovascular approach has been increasingly adopted as an alternative to surgical approach in MCA aneurysm management during the past decade. Recent endovascular series demonstrated acceptable morbidity and mortality rates but are also associated with significantly higher retreatment rates and lower occlusion rates. Microsurgical treatment of MCA aneurysms is durable and safe. Taken together, since appropriate patient selection is paramount to optimize outcomes, a microsurgical approach should still be considered as the preferred strategy in definitive MCA aneurysm management.

\section{Abbreviations}

BRAT: Barrow Ruptured Aneurysm Trial; DSA: Digital subtraction angiography; EEG: Electroencephalography; ICA: Internal cerebral artery; ICG: Indocyanine green; ICH: Intracerebral hemorrhage; ISAT: International Subarachnoid Aneurysm Trial; MCA: Middle cerebral artery; RCT: Randomized control trial; SAH: Subarachnoid hemorrhage; SSEP: Somatosensory evoked potential.

\section{Competing interests}

The authors declare that they have no competing interests.

\section{Authors' contributions}

WY contributed to the drafting of the manuscript. JH contributed to the design and revision of the manuscript. Both authors read and approved the final manuscript.

Received: 7 April 2015 Accepted: 11 May 2015

Published online: 18 August 2015

\section{References}

1. van Dijk JMC, Groen RJM, Laan Ter M, Jeltema JR, Mooij JJA, Metzemaekers JDM. Surgical clipping as the preferred treatment for aneurysms of the middle cerebral artery. Acta Neurochir (Wien). 2011;153(11):2111-7.

2. Raja PV, Huang J, Germanwala AV, Gailloud P, Murphy KPJ, Tamargo RJ. Microsurgical clipping and endovascular coiling of intracranial aneurysms: a critical review of the literature. Neurosurgery. 2008;62(6):1187-202. discussion1202-3.

3. Sturiale CL, Brinjikji W, Murad MH, Cloft HJ, Kallmes DF, Lanzino G. Endovascular treatment of distal anterior cerebral artery aneurysms: single-center experience and a systematic review. AJNR Am J Neuroradiol. 2013;34(12):2317-20.

4. Kim K-H, Cha K-C, Kim J-S, Hong S-C. Endovascular coiling of middle cerebral artery aneurysms as an alternative to surgical clipping. J Clin Neurosci. 2013;20(4):520-2.

5. Pierot L, Barbe C, Spelle L, ATENA Investigators. Endovascular treatment of very small unruptured aneurysms: rate of procedural complications, clinical outcome, and anatomical results. Stroke. 2010;41(12):2855-9.

6. Pierot L, Spelle L, Vitry F, ATENA Investigators. Immediate clinical outcome of patients harboring unruptured intracranial aneurysms treated by endovascular approach: results of the ATENA study. Stroke. 2008;39(9):2497-504.

7. Molyneux A, Kerr R, Stratton I, Sandercock P, Clarke M, Shrimpton J, et al. International Subarachnoid Aneurysm Trial (ISAT) of neurosurgical clipping versus endovascular coiling in 2143 patients with ruptured intracranial aneurysms: a randomised trial. Lancet. 2002;360(9342):1267-74.

8. McDougall CG, Spetzler RF, Zabramski JM, Partovi S, Hills NK, Nakaji P, et al. The barrow ruptured aneurysm trial. J Neurosurg. 2012;116(1):135-44.

9. Spetzler RF, McDougall CG, Albuquerque FC, Zabramski JM, Hills NK, Partovi S, et al. The barrow ruptured aneurysm trial: 3-year results. J Neurosurg. 2013;119(1):146-57.

10. Molyneux AJ, Kerr RSC, Yu L-M, Clarke M, Sneade M, Yarnold JA, et al. International Subarachnoid Aneurysm Trial (ISAT) of neurosurgical clipping versus endovascular coiling in 2143 patients with ruptured intracranial aneurysms: a randomised comparison of effects on survival, dependency, seizures, rebleeding, subgroups, and aneurysm occlusion. Lancet. 2005:366(9488):809-17

11. Molyneux AJ, Kerr RSC, Birks J, Ramzi N, Yarnold J, Sneade M, et al. Risk of recurrent subarachnoid haemorrhage, death, or dependence and standardised mortality ratios after clipping or coiling of an intracranial aneurysm in the International Subarachnoid Aneurysm Trial (ISAT): long-term follow-up. Lancet Neurol. 2009;8(5):427-33.

12. Molyneux AJ, Birks J, Clarke A, Sneade M, Kerr RSC. The durability of endovascular coiling versus neurosurgical clipping of ruptured cerebral aneurysms: 18 year follow-up of the UK cohort of the International Subarachnoid Aneurysm Trial (ISAT). Lancet. 2015;385(9969):691-7. 
13. Bakker NA, Metzemaekers JDM, Groen RJM, Mooij JJA, van Dijk JMC. International subarachnoid aneurysm trial 2009: endovascular coiling of ruptured intracranial aneurysms has no significant advantage over neurosurgical clipping. Neurosurgery. 2010;66(5):961-2.

14. Campi A, Ramzi N, Molyneux AJ, Summers PE, Kerr RSC, Sneade M, et al. Retreatment of ruptured cerebral aneurysms in patients randomized by coiling or clipping in the International Subarachnoid Aneurysm Trial (ISAT). Stroke. 2007;38(5):1538-44.

15. Rodríguez-Hernández A, Sughrue ME, Akhavan S, Habdank-Kolaczkowski J, Lawton MT. Current management of middle cerebral artery aneurysms: surgical results with a "clip first" policy. Neurosurgery. 2013;72(3):415-27.

16. Rinne J, Hernesniemi J, Niskanen M, Vapalahti M. Analysis of 561 patients with 690 middle cerebral artery aneurysms: anatomic and clinical features as correlated to management outcome. Neurosurgery. 1996;38(1):2-11.

17. UCAS Japan Investigators, Morita A, Kirino T, Hashi K, Aoki N, Fukuhara S, et al. The natural course of unruptured cerebral aneurysms in a Japanese cohort. N Engl J Med. 2012;366(26):2474-82.

18. Abla AA, Wilson DA, Williamson RW, Nakaji P, McDougall CG, Zabramski JM, et al. The relationship between ruptured aneurysm location, subarachnoid hemorrhage clot thickness, and incidence of radiographic or symptomatic vasospasm in patients enrolled in a prospective randomized controlled trial. J Neurosurg. 2014;120(2):391-7.

19. Ulm AJ, Fautheree GL, Tanriover N, Russo A, Albanese E, Rhoton AL, et al. Microsurgical and angiographic anatomy of middle cerebral artery aneurysms: prevalence and significance of early branch aneurysms. Neurosurgery. 2008;62(5 Suppl 2):ONS344-52. discussionONS352-3.

20. Dashti R, Hernesniemi J, Niemelä M, Rinne J, Lehecka M, Shen H, et al. Microneurosurgical management of distal middle cerebral artery aneurysms. Surg Neurol. 2007;67(6):553-63.

21. Dashti R, Hernesniemi J, Niemelä M, Rinne J, Porras M, Lehecka M, et al. Microneurosurgical management of middle cerebral artery bifurcation aneurysms. Surg Neurol. 2007;67(5):441-56.

22. Dashti R, Rinne J, Hernesniemi J, Niemelä M, Kivipelto L, Lehecka M, et al. Microneurosurgical management of proximal middle cerebral artery aneurysms. Surg Neurol. 2007;67(1):6-14.

23. Suzuki J, Yoshimoto T, Kayama T. Surgical treatment of middle cerebral artery aneurysms. J Neurosurg. 1984;61(1):17-23.

24. Zaidat OO, Castonguay AC, Teleb MS, Asif K, Gheith A, Southwood C, et al. Middle cerebral artery aneurysm endovascular and surgical therapies: comprehensive literature review and local experience. Neurosurg Clin N Am. 2014;25(3):455-69.

25. Unruptured intracranial aneurysms - risk of rupture and risks of surgical intervention. International study of unruptured intracranial aneurysms investigators. N Engl J Med. 1998;339(24):1725-33.

26. Greving JP, Wermer MJH, Brown RD, Morita A, Juvela S, Yonekura M, et al. Development of the PHASES score for prediction of risk of rupture of intracranial aneurysms: a pooled analysis of six prospective cohort studies. Lancet Neurol. 2014;13(1):59-66.

27. Brown RD, Broderick JP. Unruptured intracranial aneurysms: epidemiology, natural history, management options, and familial screening. Lancet Neurol. 2014;13(4):393-404.

28. Wiebers DO, Whisnant JP, Huston J, Meissner I, Brown RD, Piepgras DG, et al. Unruptured intracranial aneurysms: natural history, clinical outcome, and risks of surgical and endovascular treatment. Lancet. 2003;362(9378):103-10.

29. Chang TR, Kowalski RG, Caserta F, Carhuapoma JR, Tamargo RJ, Naval NS Impact of acute cocaine use on aneurysmal subarachnoid hemorrhage. Stroke. 2013;44(7):1825-9.

30. Diaz OM, Rangel-Castilla L, Barber S, Mayo RC, Klucznik R, Zhang YJ. Middle cerebral artery aneurysms: a single-center series comparing endovascular and surgical treatment. World Neurosurg. 2014;81(2):322-9.

31. Blackburn SL, Abdelazim AM, Cutler AB, Brookins KT, Fargen KM, Hoh BL, et al. Endovascular and surgical treatment of unruptured MCA aneurysms: meta-analysis and review of the literature. Stroke Res Treat. 2014;2014:348147.

32. Ogilvy CS, Crowell RM, Heros RC. Surgical management of middle cerebral artery aneurysms: experience with transsylvian and superior temporal gyrus approaches. Surg Neurol. 1995;43(1):15-22. discussion22-4.

33. Chyatte $D$, Porterfield R. Nuances of middle cerebral artery aneurysm microsurgery. Neurosurgery. 2001;48(2):339-46.

34. Morgan MK, Mahattanakul W, Davidson A, Reid J. Outcome for middle cerebral artery aneurysm surgery. Neurosurgery. 2010;67(3):755-61. discussion761.
35. Güresir E, Schuss P, Berkefeld J, Vatter H, Seifert V. Treatment results for complex middle cerebral artery aneurysms. A prospective single-center series. Acta Neurochir (Wien). 2011;153(6):1247-52.

36. Brinjikji W, Lanzino G, Cloft HJ, Rabinstein A, Kallmes DF. Endovascular treatment of middle cerebral artery aneurysms: a systematic review and single-center series. Neurosurgery. 2011:68(2):397-402. discussion402.

37. Bracard S, Abdel-Kerim A, Thuillier L, Klein O, Anxionnat R, Finitsis S, et al. Endovascular coil occlusion of 152 middle cerebral artery aneurysms: initial and midterm angiographic and clinical results. J Neurosurg. 2010;112(4):703-8.

38. Kadkhodayan Y, Almandoz JED, Fease JL, Scholz JM, Blem AM, Tran K, et al, Endovascular treatment of 346 middle cerebral artery aneurysms: results of a 16-year single-center experience. Neurosurgery. 2015;76(1):54-60. discussion60-1.

39. Taha MM, Nakahara I, Higashi T, Iwamuro $Y$, Iwaasa M, Watanabe $Y$, et al. Endovascular embolization vs surgical clipping in treatment of cerebral aneurysms: morbidity and mortality with short-term outcome. Surg Neurol. 2006;66(3):277-84. discussion284.

40. lijima A, Piotin M, Mounayer C, Spelle L, Weill A, Moret J. Endovascular treatment with coils of 149 middle cerebral artery berry aneurysms. Radiology. 2005;237(2):611-9.

41. Suzuki S, Tateshima S, Jahan R, Duckwiler GR, Murayama Y, Gonzalez NR, et al. Endovascular treatment of middle cerebral artery aneurysms with detachable coils: angiographic and clinical outcomes in 115 consecutive patients. Neurosurgery. 2009;64(5):876-88. discussion888-9.

42. Regli L, Uske A, de Tribolet N. Endovascular coil placement compared with surgical clipping for the treatment of unruptured middle cerebral artery aneurysms: a consecutive series. J Neurosurg. 1999;90(6):1025-30.

43. Dandy W. Intracranial arterial aneurysms. Ithaca: Comstock Publishing Company; 1969. p. 1

44. Washington CW, Ju T, Zipfel GJ, Dacey RG. Middle cerebral artery bifurcation aneurysms: an anatomic classification scheme for planning optimal surgical strategies. Neurosurgery. 2014;10 Suppl 1:145-53. discussion153-5.

45. Caplan JM, Papadimitriou K, Yang W, Colby GP, Coon AL, Olivi A, et al. The minipterional craniotomy for anterior circulation aneurysms: initial experience with 72 patients. Neurosurgery. 2014;10 Suppl 2:200-6. discussion206-7.

46. Caplan JM, Sankey E, Yang W, Radvany MG, Colby GP, Coon AL, et al. Impact of indocyanine green videoangiography on rate of clip adjustments following intraoperative angiography. Neurosurgery. 2014;75(4):437-43.

47. Choi SW, Ahn JS, Park JC, Kwon DH, Kwun BD, Kim CJ. Surgical treatment of unruptured intracranial middle cerebral artery aneurysms: angiographic and clinical outcomes in 143 aneurysms. J Cerebrovasc Endovasc Neurosurg. 2012;14(4):289-94.

48. Raza SM, Papadimitriou K, Gandhi D, Radvany M, Olivi A, Huang J. Intraarterial intraoperative computed tomography angiography guided navigation: a new technique for localization of vascular pathology. Neurosurgery. 2012;71(2 Suppl Operative):ons240-52. discussionons252.

49. Vendrell J-F, Menjot N, Costalat V, Hoa D, Moritz J, Brunel H, et al. Endovascular treatment of 174 middle cerebral artery aneurysms: clinical outcome and radiologic results at long-term follow-up. Radiology. 2009;253(1):191-8

50. Mortimer AM, Bradley MD, Mews P, Molyneux AJ, Renowden SA. Endovascular treatment of 300 consecutive middle cerebral artery aneurysms: clinical and radiologic outcomes. AJNR Am J Neuroradiol. 2014;35(4):706-14

51. Doerfler A, Wanke I, Goericke SL, Wiedemayer H, Engelhorn T, Gizewski ER, et al. Endovascular treatment of middle cerebral artery aneurysms with electrolytically detachable coils. AJNR Am J Neuroradiol. 2006;27(3):513-20. 